\title{
Uncertainty Plagues US Stem Cell Research
}

$T^{2}$ he field of human embryonic stem cell (hESC) research in the United States was thrown into confusion on August 23, with an unexpected federal court decision to halt all federal funding for hESC research. Since 1998, when the first hESC line was first established by Dr. James Thomson at the University of Wisconsin, research on these cells has generated intense public and political interest and controversy. As ESCs are able to differentiate into all mature tissue types, it is felt by many researchers and hopeful patients that the lines could ultimately be used to provide cells and organs for transplantation and drug development as well as to provide novel insights into human development and disease. As each ESC line is initiated by extracting a few 100 cells from the blastocyst stage of embryonic development, the resulting destruction of the blastocyst has prompted a level of political and legal involvement rarely seen in most biomedical research.

Since President Bush's executive order (13435) in August 2001, strict guidelines have been in place on which hESC lines could be studied using federal dollars. Under these rules, researchers could use only ESC lines already established; these blastocysts had to be produced for the purpose of in vitro fertilization and donated by consenting couples who no longer required them for pregnancy. Fewer than two dozen hESC lines proved available for study, all of which had been generated using the same technique in which the human cells are grown in contact with mouse embryonic fibroblasts. Over the next $8 \mathrm{y}$, much useful basic information was gleaned, but progress in the field was hampered by the inability to study a wider range of lines generated using newer techniques more useful for clinical translation. In response to this need, President Obama issued an executive order in March 2009 that allowed research on new lines developed since 2001. As with the previous rules, hESC lines could still not be created using federal funds, but the Obama order did permit research on lines developed with different techniques and those from blastocysts carrying specific genetic mutations discarded from preimplantation diagnosis. In fact, the current ethical guidelines under Obama, including the process of parental consent, are even more strict than those developed under President Bush with the result that several of the previously approved "Bush" lines have become ineligible.

The latest challenge to the research has come from a new interpretation by Federal Court Judge Royce Lamberth of the "DickeyWicker" act, a law that prohibits federal funding of research that involves the destruction of a human embryo. The act, included in every congressional budget since 1996 ( 2 y before the first hESC line was developed), has been interpreted until now to mean only that embryos or blastocysts cannot be destroyed with federal funds. Judge Lamberth, hearing the case of Sherley versus Sibelius, interpreted the act more broadly to cover all ESC research, and in an unexpected move, issued an injunction that all federal funding for such research must immediately stop. The story took a new twist on Thursday, September 9, when the US Court of Appeals for the D.C. Circuit stayed Lamberth's injunction, allowing funding to go ahead, at least for the short term. However, as a final decision is yet to be made on the issue, stem cell scientists and the National Institutes of Health remain confused and anxious about how to manage research budgets and ongoing experiments. Many feel that congressional action is the only definitive way to protect the future of ESC research in the United States.-Gay M. Crooks 